reach this conclusion by comparing the amount of discontinuity - 4 milligauss - with the sea-level variation of 2 milligauss observed at Huancayo. It is reasonable to suggest, therefore, that the electrical conductivity falls to zero rapidly above $105 \mathrm{~km}$.

(5) The most striking feature of these results is the fact that the total current is confined to such a narrow range of altitude. We cannot account for this high value of current density $\left(2.5 \times 10^{-10}\right.$ $\left.\theta . m . u . / \mathrm{cm}^{2}\right)$ if we assume in the conventional manner that the presence of a transverse magnetic field radically decreases the conductivity. At the magnetic equator the usual method of calculating the (westeast) D.c.-conductivity (parallel to the e.m.f. and transverse to the horizontal earth's magnetic field) leads to a value of $5 \times 10^{-18}$ e.m.u. at the level of maximum electron density ${ }^{\circ}$. From the observed current, on the other hand, we can calculate an average conductivity of $10^{-13}$ e.m.u., using commonly accepted figures for high-altitude winds and the resulting e.m.f.'s.

(6) Thus the experimental value corresponds closely to $6 \times 10^{-13}$ e.m.u., the value of conductivity calculated for the level of maximum electron density $\left(1.5 \times 10^{5}\right.$ per c.c.) in the absence of a magnetic field.

Hall effect. This discrepancy of almost a factor 1,000 between the observed and conventionally calculated conductivities can therefore be removed by ignoring the magnetic field.

It is well known ${ }^{10}$ that this procedure is justified under suitable boundary conditions. In crossed electric and magnetic fields both ions and electrons will drift in the same direction (perpendicular to both fields), the electrons at a much higher speed. The resultant Hall current may set up a polarization sufficiently large to stop further current flow; once this transient Hall current ends and the polarization is established, any influence of the magnetic field on the conductivity parallel to the applied electric field is removed. Martyn ${ }^{11}$ has suggested that this effect should be considered in calculating the conductivity of the ionospheric layers (although in the case of the $D$-layer at $75 \mathrm{~km}$. the increase brought about by neglecting the magnetic field will be quite small). Cowling and Borger ${ }^{12}$ have pointed out that, due to leakage, the polarization field may not build up sufficiently to keep a substantial steady-state Hall current from flowing and so result in only partial cancellation of the effect of the magnetic field. However, at the equator conditions may be favourable for almost complete cancellation, since the Hall current there flows perpendicularly to a horizontal magnetic field; hence a vertical polarization could be set up along a narrow equatorial strip where it would leak away only very slowly.

Conclusions. The results of the equatorial rocket measurements thus support the existence near an altitude of $100 \mathrm{~km}$. of a layer of greatly increased conductivity, probably produced by Hall polarization. This finding is in accord with Hirono' $\mathrm{s}^{13}$ prediction of a narrow, highly conducting region at the equator; it may thus account for a substantial part of the so-called anomalous $S_{q}$ variation at Huancayo.

Recent detailed measurements by Giesecke ${ }^{14}$ of the latitude-dependence of the range of the diurnal variation $\Delta H$ have established the existence of a curve with maximum near Huancayo which is much more narrowly peaked (half-width $7^{\circ}$ ) than hitherto supposed; the main features of the curve probably persist all along the magnetic equator independent of longitude. Chapman has represented this 'abnormal' peak in a phenomenological way by superimposing on the normal dynamo current system (deduced from non-equatorial stations) an additional high-intensity current of small horizontal extension flowing only at the equator, which he terms 'electrojet'. So far no certain deductions have been possible about the dimensions, and particularly about the height, of the electrojet from sea-level observations of the magnetic elements. We cannot, therefore, exclude the possibility of interpreting Giesecke's data in terms of increased equatorial current produced by the increase in conductivity, plus the Hall polarization leakage currents. Hence the electrojet may not require any special physical mechanism, but may be understood purely on the basis of the dynamo theory.

It should be pointed out that the conclusions presented here are based on a single rocket flight, at only one location, on a disturbed day $(C$-index $1 \cdot 8)$. It would be very desirable to repeat and extend these measurements of the Balfour Stewart currents in a series of rocket flights to higher altitudes, both on magnetically quiet and disturbed days, and also at various phases of the moon in order to establish the distribution of the lunar portion of the currents. The instrumentation has now been improved sufficiently to make it possible to obtain the detailed distribution of the current with altitude with considerable accuracy.

We wish to thank Prof. H. Alfvén, Prof. T. G. Cowling, Mr. W. R. Piggott, and in particular Dr. M. H. Johnson for valuable discussions. [Aug. 15.

${ }^{1}$ Singer, Maple and Bowen, J. Geophys. Res., 56, 265 (1951); Phys. Rev., 82, 957 (1951).

${ }^{2}$ Van Allen, Fraser and Floyd, Science, 108, 746 (1948).

${ }^{3}$ Maple, Bowen and Singer, J. Geophys. Res., 55, 115 (1950); Phys. Rev., 7 7\%, 398 (1950).

- Vestine, Lange, Laporte and Scott, DTM-CIW Pub., 580 (1947).

${ }^{5}$ Schuster, A., Phil. Trans. Roy. Soc., A, 238, 185 (1908). Chapman, S., and Bartels, J., "Geomagnetism" (Clarendon Press, Oxford,
1940 ).

'Balfour Stewart, "Encyclopædia Britannica", 16, 181 (9th edit.).

${ }^{7}$ Martyn, D. F., Nature, 160, 535 (1947); Proc. Roy. Soc., A, 194, 445 (1948).

${ }^{8}$ Bates, D. R., and Massey, H. S. W., J. Atm. Terr. Phys., 2, I (1951).

${ }^{9}$ Cowling, T. G., Proc. Roy. Soc., A, 183, 454 (1945), and private communication.

${ }^{10}$ Cowling, T. G., Mon. Not. Roy. Astro. Soc., 93, 90 (1933). Schlüter, A., Z. Naturforsch., 5a, 72 (1950). Alfvên, H., "Cosmical Electrodynamics" (Clarendon Press, Oxford, 1950).

${ }^{11}$ Martyn, D. F., Nature, 162, 142 (1948).

${ }^{12}$ Cowling, T. G., and Borger, R., Nature, 162, 143 (1948).

${ }^{13}$ Hirono, M., J. Geomag. Geoelectr., 2, 1 (1950); 4, 7 (, 952).

14 Giesecke, A. A., J. Geophys. Res. (in the press).

${ }^{15}$ Chapman, S., Proc. Phys. Soc., B, 64, 833 (1951); Arch. Met. Geophys. Bioklim. (in the press).

\section{COLOUR TELEVISION}

WHE sixty-seventh science meeting of the Physical Society Colour Group, held on May 14, was devoted to a discussion on visual problems in colour television. Fortunately this followed immediately on Prof. W. D. Wright's return from the United States, where among his other commitments he had discussed and witnessed demonstrations of various American colour television systems. He was therefore able to give the meeting first-hand impressions of the very considerable developments in this field on the western side of the Atlantic.

The proceedings were opened by Mr. R. G. Horner, who gave a comprehensive survey of the more feasible methods at present available for producing a colour television picture. All these are based on the conventional system of interlaced scanning, the main differences between the systems at present under 
discussion being in their colour scanning sequences, which fall broadly under three headings: (a) field sequential systems, $(b)$ line sequential systems, $(c)$ dot sequential systems. Of these, the first and third are actively in competition in the United States ; so far, there has been no real evidence of success with the second system, which appears to embody the disadvantages of the first one without the compensating advantages of the third.

In the field sequential system the picture is scainned in a succession of red, green and blue fields, and, in order to reduce flicker, it is necessary to increase the field scanning-rate by approximately three times. As the colour-changes in this system take place at relatively low speeds, it is possible to produce them by the simple and cheap expedient of revolving synchronous disks containing red, green and blue colour filters in front of the television camera and receiver cathode-ray tube. However, due to the increase in field scanning frequency, an existing monochrome receiver would be unable to receive a colour transmission even in monochrome without considerable modification to its scanning circuits.

The dot sequential system involves the most rapid rate of change of colours, so rapid, in fact, that one school of thought considers the latest form to be a truly 'simultaneous' transmission of the three primary-colour signals. While this system involves the very difficult technical problem of colour-changing at a rate of several millions per second, it offers the great advantage of requiring no change in scanningstandards, and could therefore be grafted on to an existing black-and-white system and be received in monochrome on existing receivers. Mr. Horner explained that this 'compatibility' feature is very important in the United States, where more than ten million receivers are already in the hands of the public, and programme sponsors have to be assured of the continuance of their audience when changing over to colour.

At first sight it would appear necessary to transmit about three times as much information per second for a colour picture as for a monochrome one of the same sharpness. The amount of fine detail in the picture can obviously be reduced and exchanged for colour if it is desired to keep the rate of transmission of information (band-width) constant. To a certain extent this has been the procedure adopted for recent demonstrations of the field sequential system in the United States by the Columbia Broadcasting System. The loss of sharpness incurred has been partially recovered by a new receiver circuit development known as 'crispening', and very satisfactory colour pictures have been demonstrated.

In the latest form of the dot sequential system demonstrated by the Radio Corporation of America and Hazeltine, it has been found possible to recode the three electronic primary-colour signals to give a brightness component similar to that transmitted in existing monochrome systems, the colour information being transmitted by two 'colour-difference' signals which are analogous to the familiar two dimensions of the C.I.E. colour triangle. This has been called the 'by-passed monochrome' system. As the eye is insensitive to colour in fine detail, it is therefore possible to reduce the band-width (sharpness) of the two colour-difference signals. This manœuvre is one method of achieving what is known as 'the principle of mixed highs', and permits considerable saving in band-width without apparent loss of picture quality. Further band-width reduction is being explored by interleaving the colour signals with the monochrome signal, by a method which was originally a 'dot interlaced' system and more recently a 'colour subcarrier' system. Two other American developments were referred to-the 'constant luminance' system and 'colour phase alternation' - which are refinements directed towards the reduction of spurious patterns produced by interfering signals and reduction of colour distortion.

Mr. Horner concluded his remarks by describing various solutions to the problem of changing the colours at the very high frequency necessitated by the dot sequential method. This problem is much less serious in the transmitter than in the receiver, where the question of initial cost and maintenance of the viewers' equipment is obviously an important economic factor. So far, the most successful solution appears to be the RCA tricolour cathode-ray tube. This tube contains three guns, the electron beams of which are brought into coincidence on a fluorescent screen consisting of a mosaic of triangular groups of red, green and blue phosphor dots, a total of some six hundred thousand being contained in the picture area. Between this and the electron guns, an apertured mask is accurately positioned. Each aperture centres on a group of three phosphor dots, the direction of arrival of the three beams being such that, after they have passed through the aperture mask, each beam can only excite one set of colour phosphor dots. This solution obviously involves the problem of the correct registration of the three electronic pictures on the screen of the tube. The experimental manufacture of these tubes by RCA is a major technical triumph, but many people feel that it is likely to be a very expensive design for production.

Following Mr. Horner's description of the various colour television systems, Mr. L. C. Jesty described and demonstrated some of the visual problems arising. First, with the field sequential system, the field scanning-rate has to be sufficiently high to eliminate flicker and 'colour break-up'. This was demonstrated by means of a variable-speed colourfilter disk rotating in front of a projector. With the disk running sufficiently fast to eliminate flicker, 'colour break-up' still remained and showed itself in two ways. If the viewer inadvertently moved his eyes, he saw a sequence of partially overlapping red, green and blue images. Experience has shown that the average person quickly learns to ignore this, and it is not considered to be a serious defect in the system. If an object in the picture moves rapidly across the screen, however, an effect is produced which cannot so easily be ignored. An exaggerated example of this was demonstrated by illuminating a wheel having white spokes with the projector and rotating colour-filter disk. In addition to the contrary rotation effect occurring at certain critical speeds of the wheel (as commonly seen on cinema pictures), some very striking colour patterns were produced by the spokes. A 'Kodachrome' transparency photograph of an actual field sequential colour-television picture of the wheel was then projected. This showed the same brilliantly coloured spokes, thus confirming the demonstration.

With the compatible colour sub-carrier system at present being investigated in the United States, the method of signal compression results in the appearance of a 'dot crawling' pattern on parts of the picture under certain conditions. In earlier experiments the band-width compression was achieved by simple dot-interlacing, which gave a theoretical improve- 
ment equal to halving the band-width for the same picture-detail, but at the expense of four scanning fields instead of two for the transmission of all picture elements. The resulting dot crawling or 'twinkle' on the picture and the production of additional spurious patterns from objects containing certain types of fine detail were demonstrated to the meeting in an exaggerated form by a $16-\mathrm{mm}$. film which had been recorded from the receiver screen of an experimental dot-interlaced monochrome television system. In the latest American experimental colour receivers dot patterns are now practically invisible over large areas of uniform brightness and colour, due to improvements in the method of coding the colour information.

As a final demonstration Mr. Jesty showed some colour pictures which had been kindly prepared for him by Ilford Limited (Mr. Horner), demonstrating the principles of 'by-passed monochrome' and 'mixed highs'. Two colour pictures were shown side by side for comparison, one being a normal colour transparency projected on to a screen; the other consisted of a black-and-white photographic enlargement from the original colour picture, which was illuminated by projection from a special colour transparency. The latter had been prepared by re-photographing the original colour picture with colour-sensitive material, using a black-and-white negative 'mask' of suitable quality to cancel out the greater part of the brightness differences in the colour picture. It was seen that, when this second transparency was in focus and registered with the black-and-white enlargement, it was almost indistinguishable from the normal picture alongside it. The special transparency was then progressively defocused by adjustment of its projector lens, and with certain types of picture it could be thrown badly out of focus with no noticeable loss of picture quality. The projector lens mount had been previously caljbrated in Mc./s. on the basis of the B.B.C. 405-line 3-Mc./s. picture standard. The demonstration showed that the colour components of the image could be defocused well below I Mc./s., so long as the brightness (black-and-white) component, of the image remained sharp.

Mr. Jesty concluded his remarks by stressing the necessity for a proper appraisal of alternative systems by a team of average observers, due care being taken to ensure they do not become especially skilful in their judgment, thus losing their average status.

Prof. Wright then reported on his American visit. Of the various colour television demonstrations he had seen, the field sequential system is in the most advanced state, and has given the best picture quality. He felt, however, that the potentialities of the dot sequential system are greater, particularly with regard to band-saving techniques such as in the application of the 'mixed highs' principle and, of course, in 'compatibility'. He was inclined to query if any loss in absolute definition could be tolerated in exchange for the addition of colour. He was very impressed with the technical achievement in preparing the phosphor mosaics, and in locating the mosaics, aperture mask and the three gun electrodes in correct alignment in the manufacture of the RCA tricolour cathode-ray tube.

The American television engineers have completely absorbed the C.I.E. colour triangle and are applying it with ingenuity to their colorimetry problems. Doubts are, however, beginning to arise as to the relevance of the C.I.E. data to all their problems, and colorimetrists are already becoming aware of the impact of the ideas of electronic engineers. Much remains to be learned on the subjective aspects, and the work already done in colour photography is being carefully studied. The use of an illuminated surround to the picture is being actively investigated in one laboratory. An example of the direct application of trichromatic theory to colour television is to be found in the 'low flicker primaries' used in the Columbia Broadcasting System field sequential demonstrations. By the choice of a desaturated blue primary in the receiver, they have been able to increase picture brightness without increasing flicker. The range of reproducible colours is thereby diminished, but this does not appear to give any noticeable reduction in picture quality. Again, it is possible in principle to make colour transformations from one trichromatic system to another, by means of suitable electrical circuits, and it is proposed to take advantage of this by transforming the output signals of the red-, greenand blue-sensitive cameras at the transmitter, to give correct red, green and blue modulating signals at the receiver, without the need for devising cameras having partly negative spectral sensitivity curves.

A recent American development is the LawrenceParamount tricolour tube. The screen of the tube consists of a fine grid of coloured phosphor lines, and close to this and accurately registered to it is a mesh of parallel wires, alternate wires being connected together. There are in effect, therefore, two interlaced grids. By applying suitable potentials to these, it is possible to deflect the electron beam on arrival so that it excites the required set of colour lines.

Following the three introductory papers, the meeting was thrown open for general discussion. Several speakers rajsed points relating to methods of exchanging picture-sharpness for colour. 'The general conclusion seemed to be that the eye is more sensitive to luminance differences than colour differences in regions of fine detail, particularly in actual television programmes, where other overriding distractions are present. If it is necessary to show detail colour as, for example, in a woven fabric, the technique of the 'close up' is available and would deal very adequately with any such requirement.

Dr. J. A. Darbyshire discussed the secondary advantages arising from the addition of colour to a picture, and demonstrated these by projecting some of his own colour transparencies. Colour can add materially to the impression of depth in a picture. For example, the colour of distant objects is often modified by atmospheric effects. Colour differences make small objects in the picture more visible, thus giving an impression of greater sharpness, not directly related to 'resolving power'. It can produce an atmosphere or mood which increases the viewers' appreciation, as, for example, the difference in the same scene viewed in the daytime and at sunset. The effect of adapting conditions on the choice of white in a picture was discussed by Mr. H. G. W. Harding. With a colour television receiver it would be possible to adjust this for viewing by daylight and by artificial light. Mr. G. T. Winch described his binocular viewing experiments for the appraisal of artificial illuminants. This technique might be applied to determining the best colour balance for television pictures. It was certain that faithful reproduction would not be acceptable. Dr. W. S. Stiles directed attention to the latest American proposals for a compatible system, where the reduced-definition red and blue colourdifference signals are equal in band-width. Further 
economies could be effected if the blue colourdifference signal were reduced in definition still further. The meeting having exceeded its time limit, the chairman was forced to bring to a conclusion a still lively discussion of an obviously interesting topic. L. C. JESTY

\section{OBITUARIES}

\section{Sir Charles Peers, C.B.E., F.B.A.}

Sir Charles Reed Peers, born in 1868, will be principally remembered as chief inspector of ancient monuments in the Office of Works. Educated at Charterhouse and King's College, Cambridge, he received his architectural training in the office of Sir T. G. Jackson. Peers's principal interest lay in the historical side of his profession, and he was for many years architectural editor of the "Victoria County Histories". As such he was responsible for the description of a number of important buildings, among which the scholarly and lucid accounts of the cathedrals at Winchester and Peterborough may be noted. With this experience he was an obvious choice when an inspector of ancient monuments in the Office of Works was appointed in 1910. Three years later the Act of 1913 was passed and Peers became chief inspector. The next twenty years, apart from the interruption caused by the First World War, were spent in building up and directing the services required to give effect to the provisions of the Act.

The Act of 1913 empowered the Office of Works to take over buildings, other than churches in use and inhabited houses, in order to ensure their preservation. In carrying out this work, Peers's aim was to preserve what time had left without unnecessary additions or conjeetural restoration. 'The success with which he pursued this conservative objective may be judged both from the numerous abbeys and castles for which the Ministry became responsible during his period of office, and also from the virtual cessation of the bitter controversy between the different schools of preservation, which had vexed the end of the nineteenth and the early years of the twentieth century. While it would be too much to claim that there is no criticism of the work carried out under his guidance, it is essentially a criticism of details; the main tradition which he founded is unchallenged.

Research was not a primary duty of the service established by the Act of 1913, but throughout his tenure of office Peers strove to promote the publication of works that would rouse interest in the buildings under his care. For specialists there were learned articles in scientific journals such as Archoologia, the Antiquaries Journal, and many others. For the wider public there was the admirable series of official guides to the monuments in charge of the Ministry, a series of which the larger part were from the hand of the chief inspector himself. On retirement from the Civil Service in 1933, his experience was made available to other bodies. He became surveyor of Westminster Abbey, and consulting architect to a number of important buildings such as York Minster and the Cathedral and Castle of Durham.

Peers was associated from the beginning with the work of the Royal Commission on Historical Monuments and became a commissioner in 1921. His connexion with the Society of Antiquaries was long and intimate; he served successively as secretary, director and president, and was continuously an officer from 1908 until 1934. His death has come at a time when the cause in which he spent his working life is firmly established and in good hands, a result largely due to the excellence of the foundations which he laid.

C. A. Ralegh Radford

\section{Mr. S. R. Roget}

Samuel Romilly Roget died on November 17 in the way he would have wished, suddenly and while in full harness. In spite of his seventy-seven years, he was actively engaged, on a full-time basis, in work dear to his heart-the preparation of national and international glossaries on electrical and other technical subjects. His keen interest in this sort of work is, of course, well known; not only did he publish a "Dictionary of Electrical Terms", but also he kept up to date the famous "Thesaurus of English Words and Phrases" which was compiled by his grandfather, Dr. P. M. Roget, and first published in 1852 .

Born in London in 1875, the great-grandson of a Genevese Protestant minister who came to England to be the pastor of a London Huguenot Church, Samuel Roget was educated at University College School. He studied mechanical sciences at Cambridge, and after a further year of experimental work at Cambridge went to the Woolwich works of Siemens Brothers. He remained there for seven years and then turned his attention to technical journalism. $\mathrm{He}$ was for a time assistant editor of the Electrician and afterwards of Electrical Engineering (of which he was part-proprietor) from 1906 until 1917, when publication ceased. Between the two World Wars he was a 'free lance' and occasionally contributed to Nature and other journals. He also did abstracting work for the Institution of Civil Engineers and the Institution of Electrical Engineers.

As befitted his Huguenot descent, he was a member of the Huguenot Society of London and became its honorary secretary in 1923, a post which be held until he was elected president in 1951.

In 1938 he joined the temporary part-time staff of the British Electrical and Allied Industries Research Association, and his services were placed at the disposal of the British Standards Institution to supervise the revision of the British Standard Glossary of Terms used in Electrical Engineering. In 1941 he joined the staff of the British Standards Institution, and when the revision of the glossary was completed he agreed to remain with the Institution to assist with the preparation of other glossaries and related work.

In his latter years Roget had no hobby other than his work at the British Standards Institution. After' a full day at his desk or at a committee meeting, he would often work on at the hotel in which he lived, producing documents which a less enthusiastic person would have dictated next day at the office. In this way he kept up with the work of the thirty or so committees of the Institution of which he acted as secretary, in a way which amazed his colleagues and at a pace which would have done credit to a man of half his age. With his industry he combined a quiet sense of humour and a charm of manner which endeared him to all with whom he came into contact. 